ARTICLE

https://doi.org/10.1038/s41467-019-09259-x

\title{
An Early Cretaceous enantiornithine (Aves) preserving an unlaid egg and probable medullary bone
}

\author{
Alida M. Bailleul ${ }^{1,2}$, Jingmai $\mathrm{O}^{\prime}$ Connor ${ }^{1,2}$, Shukang Zhang ${ }^{1,2}$, Zhiheng $\mathrm{Li}^{1,2}$, Qiang Wang ${ }^{1,2,3}$, \\ Matthew C. Lamanna (1) ${ }^{4}$, Xufeng Zhu ${ }^{1,2,3}$ \& Zhonghe Zhou ${ }^{1,2,3}$
}

Understanding non-crown dinosaur reproduction is hindered by a paucity of directly associated adults with reproductive traces. Here we describe a new enantiornithine, Avimaia schweitzerae gen. et sp. nov., from the Lower Cretaceous Xiagou Formation with an unlaid egg two-dimensionally preserved within the abdominothoracic cavity. Ground-sections reveal abnormal eggshell proportions, and multiple eggshell layers best interpreted as a multilayered egg resulting from prolonged oviductal retention. Fragments of the shell membrane and cuticle are both preserved. SEM reveals that the cuticle consists of nanostructures resembling those found in neornithine eggs adapted for infection-prone environments, which are hypothesized to represent the ancestral avian condition. The femur preserves small amounts of probable medullary bone, a tissue found today only in reproductively active female birds. To our knowledge, no other occurrence of Mesozoic medullary bone is associated with indications of reproductive activity, such as a preserved egg, making our identification unique, and strongly supported.

\footnotetext{
${ }^{1}$ Key Laboratory of Vertebrate Evolution and Human Origins, Institute of Vertebrate Paleontology and Paleoanthropology, 142 Xizhimenwai dajie, 100044 Beijing, China. ${ }^{2}$ CAS Center for Excellence in Life and Paleoenvironment, 100044 Beijing, China. ${ }^{3}$ College of Earth and Planetary Sciences, University of Chinese Academy of Sciences, 100049 Beijing, China. ${ }^{4}$ Section of Vertebrate Paleontology, Carnegie Museum of Natural History, Pittsburgh, PA 152134080, USA. Correspondence and requests for materials should be addressed to A.M.B. (email: alida.bailleul@ivpp.ac.cn)
} 
n nearly every aspect, modern birds (neornithines) are highly modified from the typical reptilian condition ${ }^{1}$. Although many avian skeletal features were absent in stem birds (e.g., a keeled sternum, a beak, a pygostyle), new information is making it increasingly clear that many soft-tissue and behavioral features associated with extant birds had their origins among the Dinosauria $^{2}$. Avian reproduction is no exception-birds are the only living amniotes with a single functional ovary and oviduct and are additionally characterized by proportionately large eggs ${ }^{1}$, a high degree of parental care ${ }^{1}$, and the use of medullary bone (MB), an ephemeral tissue that serves as a calcium reservoir for eggshell production during the reproductive cycle ${ }^{3-5}$. In the fossil record, adults directly associated with reproductive traces are extremely rare, but some key specimens have recently led to important discoveries about the evolution of the modern avian mode of reproduction. For example, preserved soft tissues interpreted as ovarian follicles suggest stem birds had already lost function of the right ovary ${ }^{6,7}$, and the histology of one specimen of Tyrannosaurus rex suggests that $\mathrm{MB}$ evolved well outside the avian clade $^{4,8}$

Here we describe an important new specimen of enantiornithine bird preserving a wealth of reproductive features and information, including a flattened intra-abdominal egg and traces of MB. The specimen comes from the Lower Cretaceous Xiagou Formation and represents a new taxon, Avimaia schweitzerae gen. et sp. nov. We investigate the preserved egg through standard paleohistological methods, scanning electron microscopy (SEM), and energy-dispersive $\mathrm{x}$-ray spectroscopy (EDS). We discuss the implications of these findings in context of our understanding of dinosaur reproduction and the evolution of the specialized crown avian condition.

\section{Results}

Systematic paleontology.

Aves Linnaeus, 1758

Pygostylia Chiappe, 2002

Ornithothoraces Chiappe, 1995

Enantiornithes Walker, 1981

Avimaia schweitzerae gen. et sp. nov.

Etymology. The generic name Avi- (bird) maia (mother) refers to the fact the specimen is a female preserved with an egg in the body cavity. Schweitzerae is in honor of Mary Higby Schweitzer for her ground-breaking works on MB and for her role in establishing the field of molecular paleontology.

Holotype. IVPP V25371 (Institute of Vertebrate Paleontology and Paleoanthropology), an articulated partial skeleton with some feather traces, consisting of the caudal half of the axial column, the pelvis, and the hind limbs, mostly exposed ventrolaterally (Fig. 1, Supplementary Fig. 1).

Referred specimen. CAGS-IG-04-CM-007 (Institute of Geology, Chinese Academy of Geological Sciences), a semiarticulated partial skeleton consisting of pelvic fragments and nearly complete hind limbs ${ }^{9}$.
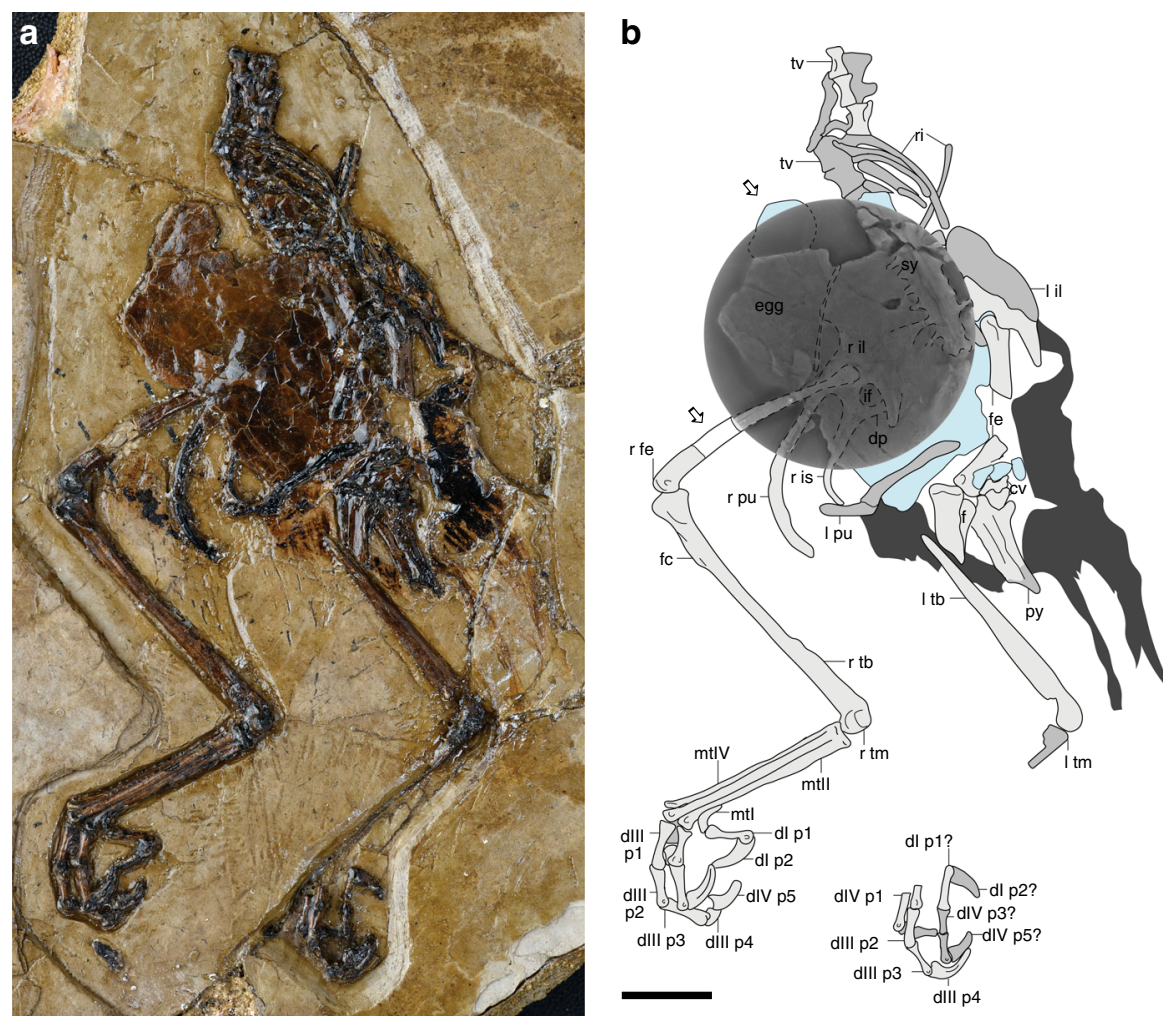

Fig. 1 Photograph and line drawing of the holotype of Avimaia schweitzerae, IVPP V25371. a Photograph of the partial skeleton with feather impressions, and the crushed preserved egg between the pubes; b interpretive line drawing, with white arrows indicating the two fragments extracted for microscopic analysis with a super-imposed CT-scan revealing the egg and underlying elements of the right pelvis in dorsal (synsacrum) and medial (ilium) view. Gray denotes bones (darker gray indicating poor preservation), blue denotes the egg, and dark gray denotes feather impressions. cv caudal vertebra, d digit, dp dorsal process, f fibula, fc fibular crest, fe femur, if ilioischiadic foramen, il ilium, is ischium, I left, mt metatarsal, p pedal phalanx, pu pubis, py pygostyle, $r$ right, ri rib, sy synsacrum, tb tibiotarsus, tm tarsometatarsus, tv thoracic vertebra. Scale bar is $1 \mathrm{~cm}$ 
Locality and horizon. Near Changma Village, Yumen City, Gansu Province, northwestern China; Lower Cretaceous (lower-middle Aptian) Xiagou Formation ${ }^{10}$.

Diagnosis. Small-bodied enantiornithine (robust, cranially forked pygostyle, distal condyles of tibiotarsus contacting medially, Jshaped metatarsal I, metatarsal IV mediolaterally reduced relative to metatarsals III and IV, metatarsal IV trochlea reduced to single condyle; Supplementary Note 1) with the following autapomorphies: pubis delicate and strongly curved so that the caudal margin is concave throughout; distal end of ischium dorsally curved.

Description. Seven thoracic vertebrae with spool-like centra precede the synsacrum, which consists of at least eight fully fused vertebrae (Fig. 1b). The synsacral neural spines, visible in the computed tomography (CT)-scans, form a low, continuous ridge on the dorsal surface (Fig. 1). Typical of enantiornithines, the pygostyle is craniodorsally forked proximally with ventrolateral processes extending most of its length ${ }^{11}$; the distal end is broken.

Fusion of the pelvis at the acetabulum cannot be determined. The cranial margin of the ilium is rounded and the dorsal margin is gently convex. The preacetabular process is longer and broader than the triangular postacetabular process (Fig. 1). Visible on the right, the dorsolateral surface forms a low ridge that is also present in Sinornis ${ }^{12}$ (Fig. 1b). The pubic peduncle of the ischium is broader than that of the ilium. The craniodorsally oriented dorsal process of the ischium contacts-but is not fused to-the ilium, demarcating an ilioischiadic foramen, as in Qiliania and PVL 4032-3 (Fundación-Instituto Miguel Lillo) ${ }^{11,13}$. The body of the ischium is distally tapered and curved dorsally. As in CAGSIG-04-CM-007 ${ }^{9}$, the pubic shaft is long and delicate and the distal third is strongly recurved such that it is orientated at nearly $90^{\circ}$ from the main portion of the shaft (ventrally deflected in Qiliania $^{13}$; robust and only weakly curved in Feitianius ${ }^{14}$ ). The distal ends are not fused but may have been in contact medially in life.

The femur is nearly straight with a posterior trochanter excavating its proximomedial surface, as in other enantiornithines ${ }^{11}$. The patellar groove is very weakly developed. The tibiotarsus is fully fused such that the ascending process of the astragalus cannot be discerned (forms a raised surface in Qiliania $^{13}$ ). The proximocaudal surface bears two tubercles previously interpreted as the facies articularis lateralis and popliteal tubercle in pengornithids ${ }^{14}$. Proximomedial excavation is probably a diagenetic artifact. The fibular crest is short $(14 \%$ the length of the tibiotarsus) and located well distal to the proximal articular surface. The distal condyles are large, round, and contact medially. The medial surface of the medial condyle is nearly flat (concave in Qiliania ${ }^{13}$ ). Only a fragment of the left fibula is preserved.

The distal tarsals are fully fused to the metatarsals, which are co-planar and unfused throughout their lengths. Metatarsal III is the longest; metatarsal IV is longer than II, which terminates level with the proximal end of the metatarsal III trochlea. Metatarsal II has a tubercle for the attachment of the $\mathrm{m}$. tibialis cranialis located one-fifth from the proximal end on the craniolateral surface contacting metatarsal III. A deep intertrochlear incision is present between metatarsals II and III, probably resultant from post-mortem plantar displacement of metatarsal II. The metatarsal II trochlea is angled so that the medial margin is proximal to the lateral margin and the trochlear condyles are only weakly separated. The trochlea of metatarsal IV is reduced to a single condyle as in most enantiornithines ${ }^{15}$. The condyle is angled plantarolaterally, extending weakly onto the dorsal surface of metatarsal III just proximal to its trochlea. Metatarsal I articulates on the medial surface of metatarsal II as in all enantiornithines. Exposed in craniomedial view, it is J-shaped with the trochlear ramus measuring approximately two-thirds of the length of the metatarsal shaft, proportionally shorter than in other enantiornithines (half of the shaft length in Qiliania ${ }^{13}$, less in Feitianius $\left.^{14}\right)$.

Pedal digit II is more robust than III and IV with a slightly larger ungual phalanx. The penultimate phalanx of digit II is 50\% longer than the first phalanx. Digit III includes three long nonungual phalanges, with the proximal and penultimate phalanges being subequal in length and longer than the intermediate phalanx. Digit IV is mostly not exposed.

Short body feathers are preserved in the caudodorsal region, extending over the pygostyle where they become slightly longer (Fig. 1). Elongate ornamental tail feathers appear to be absent.

Egg microstructure. A two-dimensionally flattened egg is preserved, laterally bound by the left and right pubes, extending caudally from the penultimate thoracic vertebra and truncating just cranial to the pygostyle (Fig. 1; Supplementary Figs. 1-2). The egg occupies an area measuring approximately $5.2 \mathrm{~cm}^{2}$ (Fig. 1) with a thickness between 200 and $400 \mu \mathrm{m}$ (Fig. 2). Two petrographic ground-sections reveal between four and six compacted layers of eggshell, highly diagenetically altered by dissolution and recrystallization (Fig. 2). EDS indicates the eggshell has been dolomitized, so that it now contains a relatively high amount of magnesium (Supplementary Note 2). Dolomitization is not uncommon in fossil eggshells ${ }^{16}$. The eggshell layers are adjacent (closely adhering) in some regions (Fig. 2d) and separated by sediments in others (Fig. 2c, f-g). The general topography and organization of the eggshell layers, the numerous breakages, and the presence of sediment between layers suggests they have undergone substantial post-mortem displacement and shear as the egg was collapsed into a two-dimensional structure (Fig. 2f).

The first ground section (Fig. 2a) reveals four distinct layers of eggshell that are each approximately $50 \mu \mathrm{m}$ thick, with the top two layers a mirror-image of the bottom two layers (Fig. 2d, e). The eggshell displays a distinctly avian microstructure ${ }^{17}$ consisting of three sub-layers: a mammillary layer with very few visible organic cores, a prismatic layer, and a very thin external layer (Fig. 2e). This tripartite organization is clearest in the two inner eggshell layers, whereas the outer eggshell layers lack visible organic cores (Fig. 2d, e). The eggshell preserved in IVPP V25371 is thinner than any previously reported enantiornithine eggshell ${ }^{17}$. The continuous layer (prismatic and external layers combined) is thinner than the mammillary layer (cl:ml ratio = $0.58: 1)$ whereas in previously reported enantiornithines ${ }^{17}$ and neornithines ${ }^{18}$, the continuous layer is thicker, typically twice the thickness of the mammillary layer (e.g., cl:ml ratio of 2:1; or $1.9: 1)^{17}$.

An additional dark brown layer is preserved in some regions (Fig. 2b). SEM and EDS indicate this layer is enriched in phosphorus compared to the rest of the eggshell, suggesting this represents part of the eggshell cuticle (Fig. 3a-c) (Supplementary Note 2), which is high in phosphorous content in extant birds ${ }^{19,20}$. EDS of the surrounding sediment confirms that this enrichment in phosphorus is endogenous to the cuticle layer and is not a contaminant (Supplementary Note 2). SEM also further indicates this layer consists of spherical nanostructures of calcium phosphate (Fig. 3c, Supplementary Note 2). Similar nanospheres are present in the cuticle of some extant birds, such as the Japanese quail (Fig. 3d), although within Neornithes cuticle nanostructures occur in a variety of shapes and sizes ${ }^{21,22}$.

Parts of what appears to be the organic shell membrane are also visible in both the petrographic slides (Fig. 2b) and SEM 
a
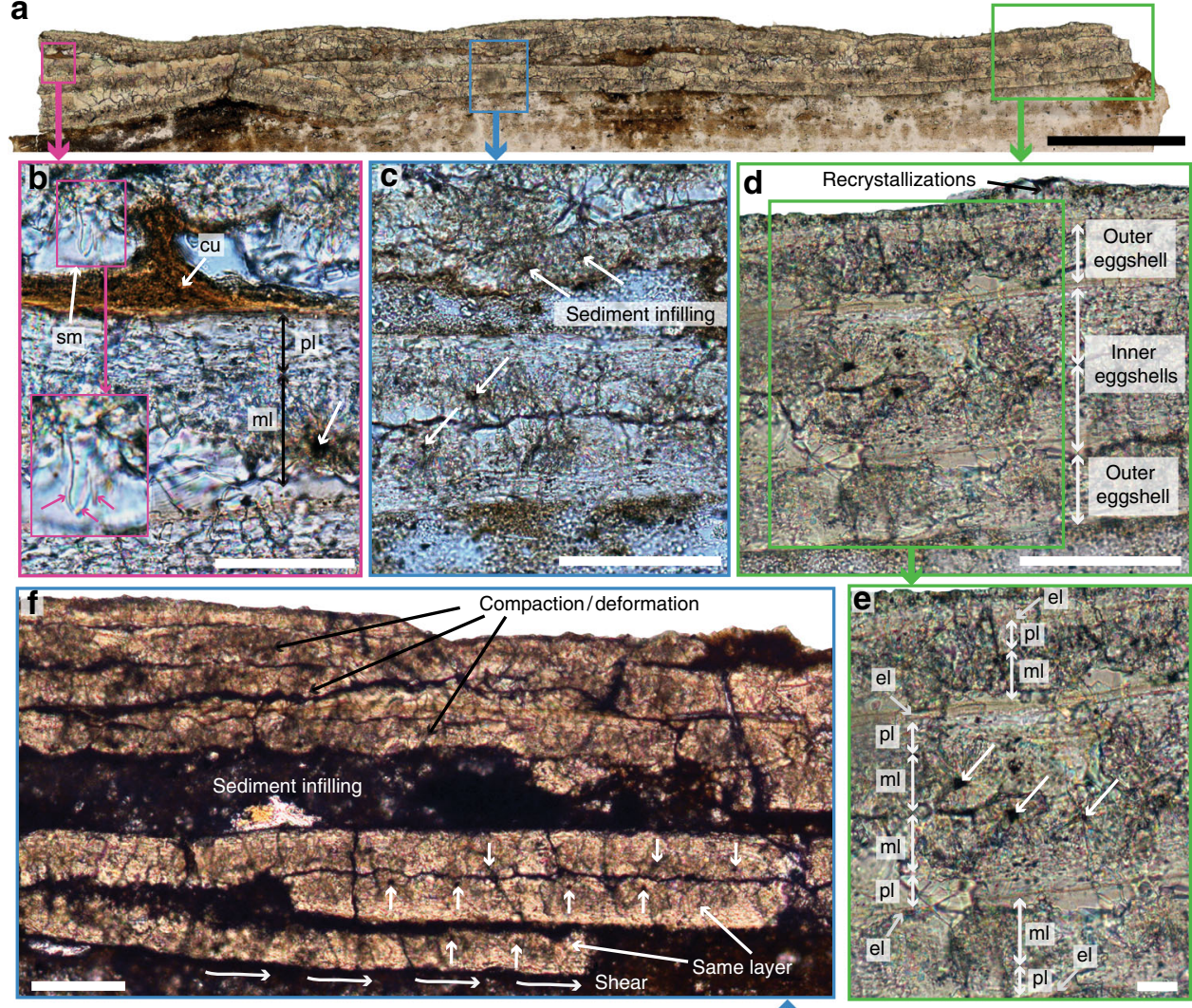

g

A

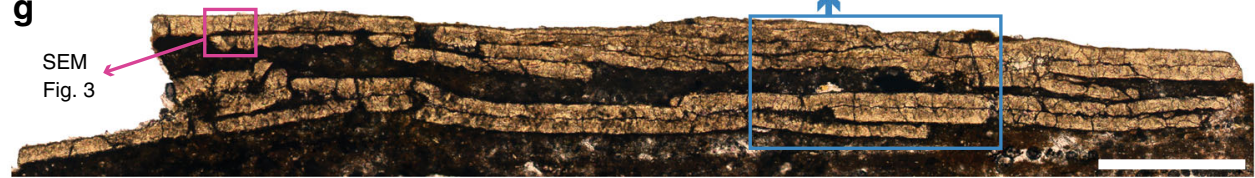

Fig. 2 Light microscopy reveals multiple layers of eggshell, compacted and disturbed by sediments. The two-dimensionally preserved egg reveals between four and six layers in cross-section (a). Parts of the cuticle (cu, dark brown layer) and shell membrane (sm) are also preserved (b). A close-up of the shell membrane (pink box) shows some fibrils (pink arrows), that are proteinaceous in living birds, but in this case might be at least partially mineralized. The eggshell layers are highly diagenetically altered $(\mathbf{c}, \mathbf{d})$. A four-layered area with a mirror-image pattern most likely represents an abnormal double-layered egg (d, e) that displays the tripartite ornithoid microstructure typically found in avian eggshells: a mammillary layer ( $\mathrm{ml}$ ) with organic cores (white arrows), a prismatic layer ( $\mathrm{pl}$ ), and an external layer (el). However, this mirror-image pattern (e) could also be the product of sediment displacement and lithostatic compaction, as exemplified in a second ground section $(\mathbf{f}, \mathbf{g})$. In this section $(\mathbf{g}$ ), sediment displacement and shear have also partially created a mirrorimage pattern, mimicking an abnormal multi-layered eggshell (f). Scale bar is $500 \mu \mathrm{m}$ in $\mathbf{a}$ and $\mathbf{g}$; $50 \mu \mathrm{m}$ in $\mathbf{b}, 100 \mu \mathrm{m}$ in $\mathbf{c}, \mathbf{d}$ and $\mathbf{f}$; and $20 \mu \mathrm{m}$ in $\mathbf{e}$

images (Fig. 3a). In neornithines, the shell membrane (also called the Membrana Testacea) consists of proteinaceous fibrils of various sizes ${ }^{23}$. In Avimaia, these fibrils are between $\sim 1.5 \mu \mathrm{m}$ (Fig. $2 \mathrm{~b}$ ) and $4 \mu \mathrm{m}$ thick (Fig. 3a). Both their size and morphology are within the range of those found in modern avian shell membrane $e^{23}$ and similar to the permineralized fibers previously reported in other dinosaur eggs, including another fossil avian eggshell from the Late Cretaceous ${ }^{24-26}$. However, EDS analysis of the shell membrane suggests that very few of the original organic components are preserved (Supplementary Note 2).

Femoral histology. Histological examination of the right femur (Fig. 4) reveals a thin compacta of nearly avascular cortical bone (CB) and the presence of very small amounts of a darker endosteal bone lining the medullary cavity, which we interpret as MB. The compacta consists almost entirely of parallel-fibered bone (Fig. 4b, d). A thin inner circumferential layer (ICL) of endosteally derived lamellar bone separates the $\mathrm{MB}$ from the $\mathrm{CB}$ (Fig. 4c). Each of these layers is separated by a clear line of resorption (Fig. 4c). Like the eggshell, the $\mathrm{CB}$ is heavily altered, displaying irregular and often confluent osteocyte lacunae (Fig.4c-d) typical of post-mortem microbial invasions ${ }^{27}$. The density of these microbial invasions is increased just below the periosteal surface (Fig. 4c), whereas a very thin band of the outermost bone (Fig. 4c) appears almost unaffected by these microbial invasions (Fig. 4c). A similar pattern is very commonly observed in archeological specimens and suggests that the postmortem microbial invasion stopped before the entirety of the bone was affected ${ }^{28}$. Under normal light the intact periosteal bone external to the microbial invasion may superficially resemble an outer circumferential layer ${ }^{29}$ (OCL), but polarized light analysis reveals no significant differences in birefringence when compared to the rest of the $\mathrm{CB}$ (Supplementary Fig. 3).

The $\mathrm{CB}$ is poorly vascularized by a very small number of longitudinal vascular canals indicating slow growth. It is interrupted by a single line of arrested growth (Fig. 4c), indicating that this specimen was at least 1-year old. Because no OCL ${ }^{29}$ is present and the ICL is proportionately thin, we infer IVPP V25371 had not reached full skeletal maturity. 

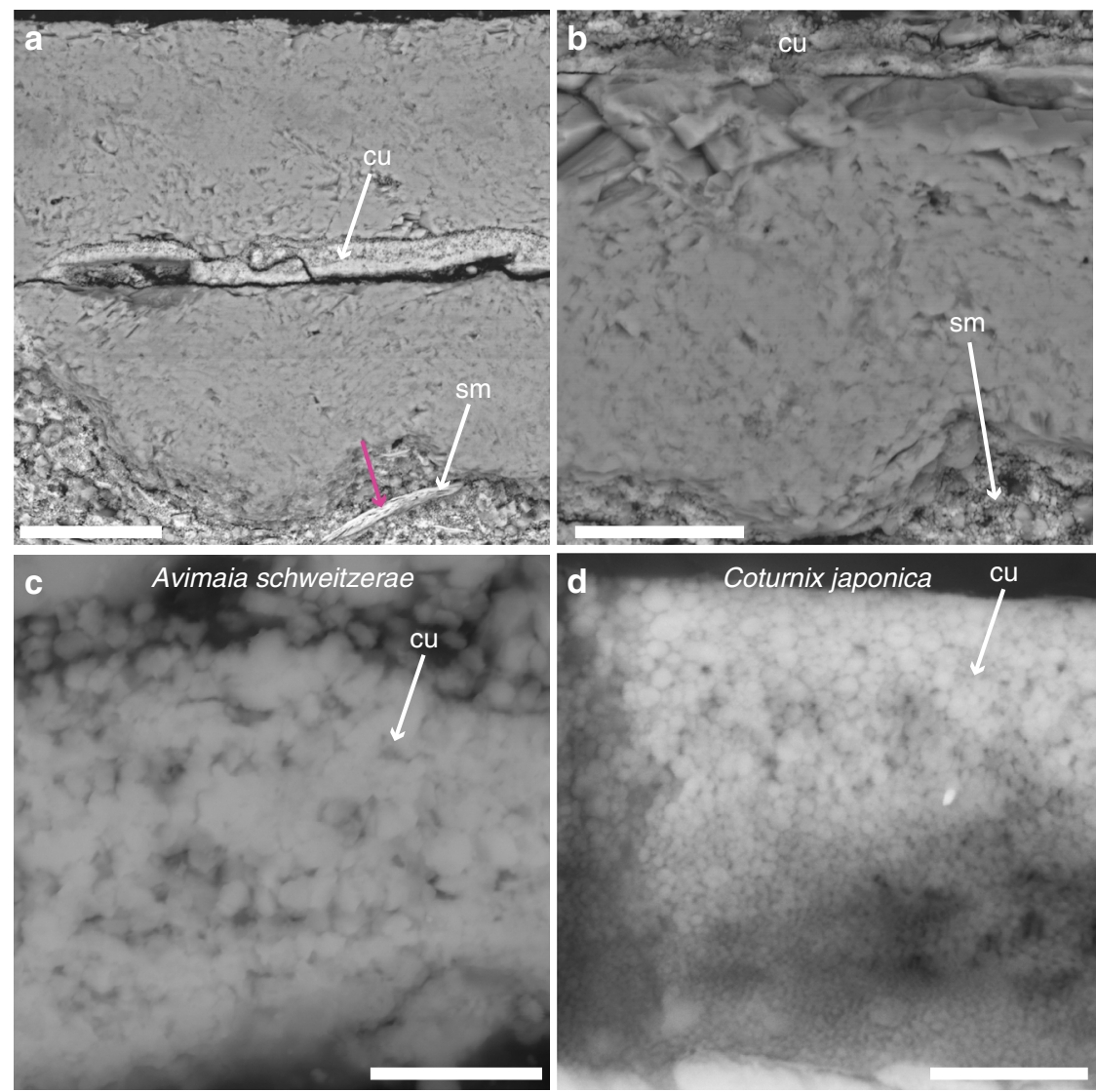

Fig. 3 SEM images showing the cuticle, eggshell, and shell membrane of the egg of Avimaia. Eggshell, cuticle, and shell membrane in cross-section (a). One fibril from the shell membrane is clearly visible (pink arrow). Close-up of the eggshell (b) and parts of the overlying cuticle and shell membrane in crosssection (b). Close-up of the cuticle of IVPP V25371, showing nanostructures of calcium phosphate (c), an adaptation found in modern birds, such as the Japanese quail, Coturnix japonica (d), to protect the embryo in infection-prone environments. It also represents the hypothesized ancestral morphological condition for avian cuticles. Abbreviations: same as Fig. 2. Scale bar is $50 \mu \mathrm{m}$ in $\mathbf{a}, 20 \mu \mathrm{m}$ in $\mathbf{b}, 3 \mu \mathrm{m}$ in $\mathbf{c}$, and $2 \mu \mathrm{m}$ in $\mathbf{d}$

At low magnification, the MB consists of a thin, dark brown layer, with some short trabeculae extending into the medullary cavity (Fig. 4). The MB can clearly be distinguished by its color from the lighter colored $\mathrm{CB}$. The endosteal surface of the $\mathrm{MB}$ is scalloped, indicating active resorption at the time of death (Fig. 4c). The MB has very few osteocyte lacunae and those present are elongated (Fig. 4d). Polarized light reveals a lamellar organization of the collagen fibers (Fig. 4d).

Interpretation of preserved eggshell. We interpret the entire preserved eggshell structure as a single egg with an additional, abnormal layer of eggshell, that has been crushed flat and disturbed by sediments during diagenesis. Although multiple layers are preserved, if two eggs were present the top two eggshell layers should mirror each other, as should the bottom two layers. Instead the top two layers mirror the bottom two layers (Fig. 2e). Although only one small fragment of the egg was histologically sampled, the entire structure was analyzed through CT and the data show no indication that a second egg was present (Supplementary Fig. 2). Our interpretation that only a single egg is present is consistent with evidence from preserved soft-tissue and nests that suggest stem birds (and possibly troodontids) had only a single functional ovary and would have laid one egg per day ${ }^{7}$.

Four closely adhering layers of eggshell with the top two layers mirroring the bottom two layers (Fig. $2 \mathrm{~d}$, e) are not apparent throughout the entirety of the ground-sections (Fig. 2c, f, g). In some areas only two mirrored layers are visible with additional layers present but separated by matrix and not forming a clearly double-layered (on top and bottom) structure (Fig. 2c). There are two possible interpretations: either the second layer of eggshell detached from the inner layer during diagenesis in some regions (and was lost in some areas), which frequently occurs in the extra layers of modern bird eggs when this abnormality is reported ${ }^{30,31}$, or the four-layered, mirror-image pattern observed in the first section (Fig. 2d, e) is the product of complex lithostatic compaction, post-mortem folding, and sediment displacement of a single-layered eggshell. It is often difficult to make this differentiation in fossils $s^{32,33}$. In the second ground section (Fig. 2f, g), the bottom-most layer has clearly been displaced and sheared and in fact belongs to the layer now located above it (Fig. 2f). This exemplifies how sediment displacement can create a mirrorimage pattern mimicking a multilayered egg.

Additional CT-scan data with extremely high-resolution capable of reconstructing the layers throughout the entire egg may be able to distinguish between these two hypotheses in the future. However, three lines of evidence indicate that at this time, the preserved structure is best interpreted as an abnormal, doubleshelled egg that has been somewhat obscured by diagenesis. First, the observed eggshell layers are not morphologically consistent throughout: the mammillary layer in the outer layers of eggshell lacks visible organic cores and it appears only the inner layer has cuticle (Fig. 2d, e). If the layers are all from a single-layered egg this difference in morphology between inner and outer layers should not exist. Secondly, the absence of visible organic cores only in the outer layers strongly suggests that fewer nucleation 

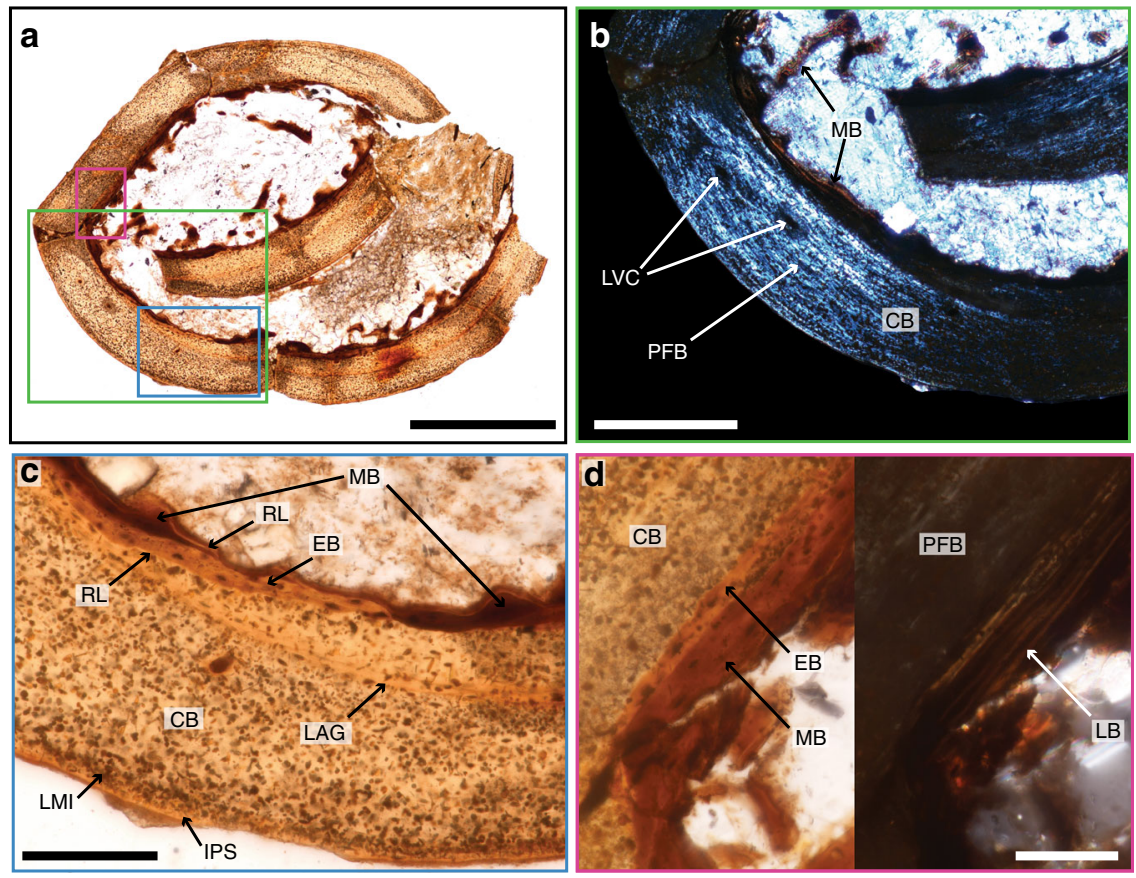

Fig. 4 Histology reveals the presence of small amounts of medullary bone (MB) in the femur of Avimaia. Natural light (a, c, d-left image) and polarized light microscopy (b, d-right image) show slow growing, parallel-fibered and almost avascular cortical bone (CB), and small, endosteal trabeculae of lamellar MB (which are much darker than the CB and the endosteal bone, EB) extending into the medullary cavity. Other abbreviations: IPS intact periosteal surface, LAG line of arrested growth, LB lamellar bone, LMI layer of microbial invasion, LVC longitudinal vascular canal, PFB parallel-fibered bone, RL resorption line. Scale bar is $500 \mu \mathrm{m}$ in $\mathbf{a}, 200 \mu \mathrm{m}$ in $\mathbf{b}, 100 \mu \mathrm{m}$ in $\mathbf{c}$, and $50 \mu \mathrm{m}$ in $\mathbf{d}$

sites were available during the formation of the outer eggshell layer. This often occurs in the outer layers of abnormal multilayered non-avian dinosaur eggs ${ }^{34}$. Finally, the proportions of the layers making up the eggshell microstructure are atypical further supporting inferences that the reproductive system in this individual was disrupted. In all healthy neornithine eggs ${ }^{18,35}$ and in previously reported enantiornithine eggs ${ }^{17}$, the continuous layer is thicker than the mammillary layer (typically cl:ml ratio $=2: 1$ ), whereas the opposite condition is present in IVPP V25371 (cl:ml ratio $=0.58: 1$ ). The presence of a cuticle (Figs. $2 b, 3$ ) indicates that the formation of the continuous layer had terminated and that its unusually thin morphology is not because it was incomplete. This strongly suggests that the reproductive system of Avimaia IVPP V25371 was not functioning normally, supporting interpretations regarding additional egg abnormalities.

\section{Discussion}

Reports of dinosaur specimens preserved with eggs, or other key reproductive features such as ovarian follicles, preserved within the body cavity, are extremely rare $7,36,37$. The holotype of A. schweitzerae is the only fossil bird ever reported with an unlaid, intra-abdominal egg. The total evidence from the preserved eggshell microstructure combined with histological data inform on a number of important evolutionary questions pertaining to the origins of the specialized form of reproduction present in modern birds (Fig. 5).

The eggshell preserved in IVPP V25371 is abnormally thin, as indicated by the unusual proportions of the continuous layer relative to the mammillary layer. Eggshell thinning in extant birds is often attributed to environmental pollutants ${ }^{38}$ but can also be caused by a hormonal imbalance ${ }^{39}$. The egg is also best interpreted as having two layers of eggshell (Fig. 2e). Multilayered (including double-layered) eggs are common in non-avian dinosaurs and in both fossil and extant turtles, and are commonly referred in the literature as pathological or abnormal ${ }^{31,32,34,40}$. Because these types of eggs have been described in fossils more extensively than in extant species, more data are necessary to fully understand the cause of these numerous abnormalities preserved in the fossil record $^{41}$. However, multilayered eggs clearly do not represent the normal, healthy condition. It has been suggested that they represent an ubiquitous response to stress in the many lineages in which they occur ${ }^{31,34}$.

Modern eggs with multiple layers of eggshell are caused by abnormal, prolonged retention in the oviduct, which is often attributed to various types of physiological and/or environmental stresses $^{31,41-45}$. Although this condition is common in non-avian dinosaurs and turtles ${ }^{31,32,34,40}$, multilayered eggshells appear to be comparatively rare in modern birds, to our knowledge only reported in a handful of species (the chicken ${ }^{44,46,47}$, the Herring Gull $^{48}$, the Japanese Quail ${ }^{31}$ and the Tropical mockingbird ${ }^{30}$ ), and this condition has not been previously reported in any fossil bird. If this is not the product of a sampling bias, it is unclear why this condition would be less common in Neornithes compared to more basal reptiles but it may be related to physiological changes in crownward avians.

In modern birds, the eggshell cuticle reportedly only forms an hour before oviposition ${ }^{49}$. Avimaia IVPP V25371 appears to preserve parts of the cuticle layer. If our interpretation is incorrect and the egg is not multilayered, this suggests eggshell formation was completed but the bird died within the hour after cuticle formation before oviposition. However, we infer that the eggshell is double-layered and note that the cuticle only appears to be present on the inner eggshell layer (Figs. 2, 3). This strongly suggests that after eggshell formation was complete (as evidenced by the cuticle), the egg was abnormally retained within the oviduct where it received a second layer of eggshell. This evidence suggesting prolonged egg retention, together with the fact the egg is preserved still inside the body, brings us to speculate that Avimaia IVPP V25371 may have suffered from a serious 


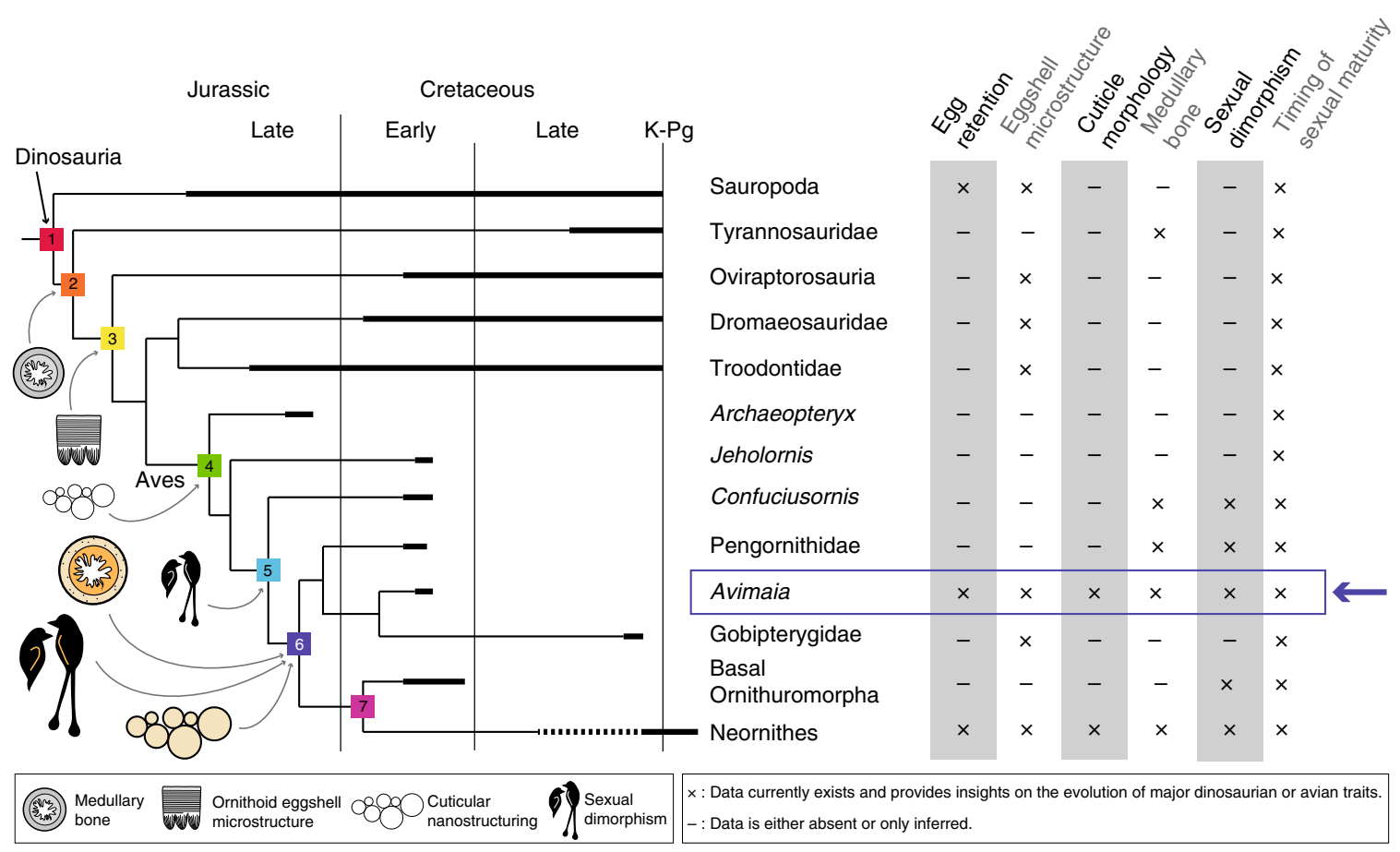

Fig. 5 Simplified phylogeny with hypothetical evolutionary stages of modern avian reproduction. Stage 1: Plesiomorphic dinosaurian condition: abnormal multilayered eggshells due to egg retention can occur ${ }^{34}$, dinosauroid eggshell microstructure ${ }^{35}$, possible sexual dimorphism ${ }^{75}$, strong histological evidence for sexual maturity occurring prior to skeletal maturity ${ }^{63}$. Stage 2: Possible appearance of medullary bone ${ }^{4,8}$. Stage 3: Possible appearance of ornithoid eggshell microstructure ${ }^{35}$. Stage 4: Possible appearance of cuticular nanostructuring ${ }^{21}$. Stage 5: Strong evidence for sexual dimorphism (inferred sexually dimorphic feathers, e.g., ref. ${ }^{65}$ ). Stage 6: In Avimaia: presence (not necessarily first occurrence) of cuticular nanostructuring, medullary bone, and a plesiomorphic non-avian dinosaur-like timing of sexual maturity within Aves. Further support for the presence of sexually dimorphic plumage. Stage 7: Avian-like timing of sexual maturity, skeletal maturity occurs prior to sexual maturity (probably evolved multiple times in parallel in Ornithuromorpha64)

condition known as egg binding (also referred to as egg impaction). This condition, in which the egg becomes completely stuck inside the body, is a form of aggravated egg retention ${ }^{42,45}$. Egg binding is common in small, domestic birds ${ }^{45,50}$, also occurring in the wild ${ }^{51}$, and typically results in death unless the egg is manually or surgically extracted. Thus, it is possible that IVPP V25371 died as a direct result of the abnormal egg preserved inside it. If correct, this would represent the oldest documented occurrence of this common reproductive disorder. The alternative hypothesis, based on the timing of cuticle formation of healthy avian eggs ${ }^{49}$, that Avimaia IVPP V25371 died within the hour before oviposition due to causes unrelated to egg retention or binding, while gravid with an abnormal egg, is possible but seems less likely given the multiple lines of evidence indicating dysfunction of the reproductive system.

The egg preserved in Avimaia IVPP V25371 also offers insight into the evolution of the avian cuticle. Fossilized cuticles are rarely reported, but remnants are known from non-avian theropod $^{20}$ and enantiornithine ${ }^{17,52}$ eggshells. However, none reported the presence of nanospheres of calcium phosphate (Fig. 3c). In neornithines these nanospheres play multiple roles in the survival of the developing embryo (e.g., Fig. 3d), including critical antimicrobial defense ${ }^{21,22}$. Although most modern birds lack nanospheres in their cuticle, nanostructuring has been hypothesized to represent the ancestral avian condition ${ }^{21}$ (Fig. 5). This hypothesis is supported by the discovery of nanospheres in the cuticle preserved in Avimaia (Fig. 3c). Similar nanospheres most commonly occur in modern taxa that nest in humid, infection-prone environments (e.g., nests near water, or buried ${ }^{21}$ ); therefore, we hypothesize a similar nesting ecology for Avimaia. This also corroborates data from preserved enantiornithine nests, which suggests the eggs were partially buried ${ }^{53}$. Future biomolecular analyses, such as investigation of the eggshell pigment, may allow further insights into the nesting ecology of Avimaia ${ }^{54,55}$.

Because IVPP V25371 represents a gravid female bird, we anticipated the presence of $\mathrm{MB}$, a labile tissue that forms endosteally in cancellous spaces throughout the skeleton in ovulating and gravid female birds, providing a calcium reservoir for eggshell formation $^{3,5}$ (Fig. 4). MB was first reported outside Neornithes in the non-avian theropod Tyrannosaurus rex, indicating this reproductive specialization evolved far outside of Aves ${ }^{4,8}$ (Fig. 5). Since this discovery, $\mathrm{MB}$-or MB-like tissues-have been reported in an even broader phylogenetic sample, including ornithischian dinosaurs and pterosaurs ${ }^{56,57}$. However, because MBlike endosteal tissues can form for a number of reasons not necessarily related to reproduction (e.g., ref. ${ }^{58}$ ), no previous report of fossil $\mathrm{MB}$ can claim to be unequivocal within the framework of our current understanding of this reproductive tissue $^{57}$. Among stem birds, $\mathrm{MB}$ has previously been reported in the fossil bird Confuciusornis ${ }^{59}$ and a pengornithid enantiornithine, both from the Jehol Biota ${ }^{57}$. The purported MB in Confuciusornis does not hold up to scrutiny and the pengornithid, although a very strong case is made, lacks irrefutable signs of reproductive activity (see discussion in ref. ${ }^{57}$ ). IVPP V25371 preserves unequivocal evidence of reproductive activity and lacks indication of bone pathology (i.e., it has a smooth periosteum). Therefore, Avimaia IVPP V25371 provides the strongest evidence to date for MB occurring outside crown birds (Fig. 5).

In modern birds, MB is usually woven ${ }^{4,8}$ or parallel-fibered ${ }^{60}$, but it can also present a lamellar organization ${ }^{61}$. Information from this specimen and a previously described enantiornithine $\mathrm{s}^{57}$ suggests that $\mathrm{MB}$ may have formed more slowly in enantiornithines compared to similarly sized neornithines. This is 
consistent with $\mathrm{CB}$ deposition, which is slower in enantiornithines compared to crown birds ${ }^{62}$. The MB in Avimaia appears to have formed more slowly than that reported in another Early Cretaceous enantiornithine ${ }^{57}$, which likely represents intraspecific variation. The femoral histology indicates IVPP V25371 was not rapidly growing but also that it had not fully reached skeletal maturity at the time of death. This provides further evidence in support of hypotheses that non-ornithurine birds, like non-avian dinosaurs but unlike extant birds, reached reproductive maturity before somatic maturity 59,63-65 (Fig. 5). This has been demonstrated in non-avian dinosaurs based on specimens preserved while brooding ${ }^{66}$. Although widely speculated to also be true in non-ornithurine birds (and in some cases supported by purported occurrences of $\mathrm{MB})^{56,59}$, this specimen provides additional evidence that reproductive maturity preceded skeletal maturity in stem birds.

Lastly, the holotype of Avimaia appears to lack elongated tail feathers (Fig. 1), which lends support to inferences regarding the sexual dimorphism of elongate tail feathers in enantiornithines (Fig. 5). Some specimens of confuciusornithiforms and enantiornithines preserve elongate rachis-dominated tail feathers (RDFs), which are widely considered to be sexually dimorphic features and present only in males ${ }^{65,67}$. Support for this interpretation comes from the purported preservation of ovarian follicles in one enantiornithine $e^{6,7}$ and medullary bone in one Confuciusornis $^{59}$, but the identification of female specific tissue in both cases is still controversial ${ }^{57,68}$. Consistent with preserved indicators that IVPP V25371 is female (egg, MB), RDFs are absent. It is possible the absence of RDFs in IVPP V25371 is preservational (as is the case in all described specimens lacking this feature), given that feathers are not well preserved in this specimen. An absence due to seasonal differences in plumage is unlikely-if these feathers are in fact a sexual characteristic, they would be expected to be present either year-round (as suggested by their presence in very young juveniles ${ }^{69}$ ) or only present in the breeding plumage. Since IVPP V25371 was clearly breeding, the absence of RDFs in this specimen is most likely either a true absence or taphonomic artifact. If this is a true absence, the holotype of Avimaia then also supports previous hypotheses that such features are sexually dimorphic and only present in male enantiornithines 67 .

\footnotetext{
Methods

Phylogenetic analysis. We explored the phylogenetic position of IVPP V25371 (Supplementary Figure 4) using an expanded version of the O'Connor and Zhou ${ }^{70}$ dataset ${ }^{15}$ that includes seven additional tarsometatarsal characters (Supplementary Note 1) and revised cranial scorings for Ichthyornis based on recently published data $^{71}$. We included all previously described enantiornithines from the Xiagou Formation: Qiliania, Feitianius, Dunhuangia, GSGM CAGS-IG-07-CM-001, CAGS-IG-02-0901, CAGS-04-CM-023. Information from CAGS-04-CM-007 was combined with IVPP V25371 for the operational taxonomic unit (OTU) Avimaia. CAGS-04-CM- $023^{72}$ had to be removed because inclusion of this specimen resulted in the collapse of Ornithothoraces. The final matrix consists of 41 taxa, 25 of which are enantiornithines, scored across 252 characters, 31 of which are ordered, which we analyzed using $\mathrm{TNT}^{73}$. Early avian evolution is extremely homoplastic; thus, we explored the effects on the matrix of using implied weighting at various $k$ values $(k=1,3,12,16)^{74}$. We found that the results using a priori weights were identical to those using implied weighting with the recommended $k$ value of $16^{74}$. Lower $k$ values created a slightly larger polytomy among derived enantiornithines.

In the presented analysis we conducted a heuristic search using tree-bisection reconnection (TBR) retaining the single shortest tree from every 1000 followed by a second round of TBR. The first round produced two trees 709 steps long; a second round of TBR produced 44 trees of the same length.
}

Surface area calculations. The surface area occupied by the flattened egg was calculated using a scaled photograph into the software Illustrator CS6 and the arealength plug-in.
Paleohistology-petrographic ground-sections. The two fragments (from the eggshell and the femur, Supplementary Figure 2) were extracted with a rotating tool equipped with a diamond blade (Dremel 8100). Subsequently, the fragments were prepared using the paleohistological ground-sectioning technique: Samples were embedded in EXAKT Technovit 7200 (Norderstedt, Germany) one-component resin, and cured for $24 \mathrm{~h}$, cut using an EXAKT $300 \mathrm{CP}$ accurate circular saw, and then ground and polished using the EXAKT 400CS grinding system (Norderstedt, Germany) until the desired optical contrast was reached (between 20 and $30 \mu \mathrm{m}$ ). Sections were observed under both natural and elliptically polarized light using a ZEISS AX10 light microscope (Thornwood, USA). Photographs were taken using the camera ZEISS AxioCam MRc5 (Thornwood, USA) and the software Axio Vision SE64 (Rel. 4.9). We used the "photomerge" tool in Adobe Photoshop CS6 to reconstruct the entire sections.

SEM and EDS. SEM was taken at Chinese Academy of Geological Sciences using FEI Quanta 450 (FEG) at $20 \mathrm{kv}$. For the fossil egg, petrographic ground-sections were used, but for the extant comparison of the Japanese quail cuticle (Coturnix japonica; Fig. 3d), we used a fragment of eggshell embedded in a polished, resin block (EXAKT Technovit 7200 (Norderstedt, Germany). The Japanese quail egg fragment was taken from a complete egg obtained commercially. This species was specifically chosen for its cuticle morphology (with nanostructures of calcium phosphate) based on two previous studies ${ }^{21,22}$. Both BSE and SE modes (backscattered electrons and secondary electrons) were applied and EDS was calculated for several spots (Supplementary Figure 5) showing different structures (Supplementary Note 2, Supplementary Figs. 5-11, Supplementary Table 1).

$\boldsymbol{\mu}$ Computed tomography. The egg of IVPP V25371 was scanned twice. The longitudinal scan (with a resolution of $15.49 \mu \mathrm{m}$ ) (Fig. 2b; Supplementary Figure $2 \mathrm{~b}$ ) was obtained from a 160-Micro-CL (Computed Laminography) at the IVPP (Beijing China). The cross-sectional CT scans $(15.7 \mu \mathrm{m})$ (Supplementary Figure 2c) were obtained from an industrial CT scanner Phoenix v|tome|x (Shanghai, China). CT scans were observed and photographs were taken using the software VGSTUDIO MAX (2.0).

Nomenclatural acts. This published work and the nomenclatural acts it contains have been registered in ZooBank, the proposed online registration system for the International Code of Zoological Nomenclature (ICZN). The ZooBank LSIDs (Life Science Identifiers) can be resolved and the associated information viewed through any standard web browser by appending the LSID to the prefix "http://zoobank. org/". The LSIDs for this publication are: urn:Isid:zoobank.org:act:66CA308407B6-47F9-8F8D-3CC27C72678D.

Reporting summary. Further information on experimental design is available in the Nature Research Reporting Summary linked to this article.

\section{Data availability}

IVPP V25371 is reposited at the Institute of Vertebrate Paleontology and Paleoanthropology in Beijing. All data are available upon reasonable request.

Received: 6 December 2018 Accepted: 1 March 2019

Published online: 20 March 2019

\section{References}

1. Gill, F. Ornithology (WH Freeman and Company, New York, 2007).

2. Brusatte, S. L., O'Connor, J. K. \& Jarvis, E. D. The origin and diversification of birds. Curr. Biol. 25, R888-R898 (2015).

3. Bloom, W., Bloom, M. A. \& McLean, F. C. Calcification and ossification. Medullary bone changes in the reproductive cycle of female pigeons. Anat. Rec. 81, 443-475 (1941)

4. Schweitzer, M. H., Wittmeyer, J. L. \& Horner, J. R. Gender-specific reproductive tissue in ratites and Tyrannosaurus rex. Science 308, 1456-1460 (2005).

5. Taylor, T. \& Moore, J. Avian medullary bone. Nature 172, 504 (1953).

6. O'Connor, J. K., Zheng, X., Wang, X., Wang, Y. \& Zhou, Z. Ovarian follicles shed new light on dinosaur reproduction during the transition towards birds. Natl. Sci. Rev. 1, 15-17 (2013).

7. Zheng, X. et al. Preservation of ovarian follicles reveals early evolution of avian reproductive behaviour. Nature 495, 507 (2013)

8. Schweitzer, M. H., Zheng, W., Zanno, L., Werning, S. \& Sugiyama, T. Chemistry supports the identification of gender-specific reproductive tissue in Tyrannosaurus rex. Sci. Rep. 6, 23099 (2016).

9. Lamanna, M. C. et al. A partial skeleton of an enantiornithine bird from the Early Cretaceous of northwestern China. Acta Palaeontol. Pol. 51, 423-434 (2006). 
10. Suarez, M. B., Ludvigson, G. A., González, L. A., Al-Suwaidi, A. H. \& You, H.-L. Stable isotope chemostratigraphy in lacustrine strata of the Xiagou Formation, Gansu Province, NW China. Geol. Soc. Lond., Spec. Publ. 382, 143-155 (2013).

11. Chiappe, L. M. \& Walker, C. A. Mesozoic Birds: Above the Heads of Dinosaurs 240-267 (University of California Press, Berkeley, CA, 2002).

12. Sereno, P., Rao, C. \& Li, J. Mesozoic Birds: Above the Heads of Dinosaurs 184-208 (University of California Press, Berkeley, CA, 2002).

13. Ji, S.-A. et al. A new, three-dimensionally preserved enantiornithine bird (Aves: Ornithothoraces) from Gansu Province, north-western China. Zool. J. Linn. Soc. 162, 201-219 (2011).

14. O'Connor, J. K. et al. A new Early Cretaceous enantiornithine (Aves, Ornithothoraces) from northwestern China with elaborate tail ornamentation. J. Vertebr. Paleontol. 36, e1054035 (2016).

15. Atterholt, J., Hutchison, J. H. \& O’Connor, J. K. The most complete enantiornithine from North America and a phylogenetic analysis of the Avisauridae. PeerJ 6, e5910 (2018)

16. Jain, S., Bajpai, S., Kumar, G. \& Pruthi, V. Microstructure, crystallography and diagenetic alteration in fossil ostrich eggshells from Upper Palaeolithic sites of Indian peninsular region. Micron 84, 72-78 (2016)

17. Varricchio, D. J. \& Barta, D. E. Revisiting Sabath's "larger avian eggs" from the Gobi Cretaceous. Acta Palaeontol. Pol. 60, 11-25 (2014).

18. Hincke, M. T. et al. The eggshell: structure, composition and mineralization. Front. Biosci. 17, 120 (2012)

19. Cusack, M., Fraser, A. C. \& Stachel, T. Magnesium and phosphorus distribution in the avian eggshell. Comp. Biochem. Physiol. Part B: Biochem. Mol. Biol. 134, 63-69 (2003).

20. Yang, T.-R., Chen, Y.-H., Wiemann, J., Spiering, B. \& Sander, P. M. Fossil eggshell cuticle elucidates dinosaur nesting ecology. PeerJ 6, e5144 (2018).

21. D’Alba, L., Maia, R., Hauber, M. E. \& Shawkey, M. D. The evolution of eggshell cuticle in relation to nesting ecology. Proc. R. Soc. B 283, 20160687 (2016).

22. D'Alba, L. et al. What does the eggshell cuticle do? A functional comparison of avian eggshell cuticles. Physiol. Biochem. Zool. 90, 588-599 (2017).

23. Hincke, M. T., Nys, Y. \& Gautron, J. The role of matrix proteins in eggshell formation. J. Poult. Sci. 47, 208-219 (2010).

24. Fernández, M. S. \& Salgado, L. The youngest egg of avian affinities from the Cretaceous of Patagonia. Hist. Biol. 1-9, https://doi.org/10.1080/ 08912963.2018.1470622 (2018).

25. Grellet-Tinner, G. Membrana testacea of titanosaurid dinosaur eggs from Auca Mahuevo (Argentina): implications for exceptional preservation of soft tissue in Lagerstätten. J. Vertebr. Paleontol. 25, 99-106 (2005).

26. Varricchio, D. J., Horner, J. R. \& Jackson, F. D. Embryos and eggs for the Cretaceous theropod dinosaur Troodon formosus. J. Vertebr. Paleontol. 22, 564-576 (2002).

27. Jans, M. M. Current Developments in Bioerosion 397-413 (Springer, New York, 2008).

28. Fernández-Jalvo, Y. et al. Early bone diagenesis in temperate environments: Part I: surface features and histology. Palaeogeogr. Palaeoclimatol. Palaeoecol. 288, 62-81 (2010).

29. Ponton, F. et al. Variation of the outer circumferential layer in the limb bones of birds. Acta Ornithol. 39, 137-140 (2004).

30. Hayes, F. E. A partial double-layered eggshell in the tropical mockingbird (Mimus gilvus). Ornitol. Neotrop. 16, 263-266 (2005).

31. Jackson, F. D. \& Varricchio, D. J. Abnormal, multilayered eggshell in birds: implications for dinosaur reproductive anatomy. J. Vertebr. Paleontol. 23, 699-702 (2003).

32. Jackson, F. D. \& Schmitt, J. G. Recognition of vertebrate egg abnormalities in the Upper Cretaceous fossil record. Cretac. Res. 29, 27-39 (2008).

33. Grellet-Tinner, G., Corsetti, F. \& Buscalioni, A. The importance of microscopic examinations of eggshells: discrimination of bioalteration and diagenetic overprints from biological features/Importancia de la microscopia en el examen de cascaras de huevos: discriminacion entre bioalteracion y senales diageneticas de las caracteristicas biologicas. J. Iber. Geol. 36, 181-193 (2010).

34. Jackson, F. D. et al. Abnormal, multilayered titanosaur (Dinosauria: Sauropoda) eggs from in situ clutches at the Auca Mahuevo locality, Neuquén Province, Argentina. J. Vertebr. Paleontol. 24, 913-922 (2004).

35. Mikhailov, K. E. Classification of fossil eggshells of amniotic vertebrates. Acta Palaeontol. Pol. 36, 193-238 (1991)

36. Chen, P.-j., Dong, Z.-m. \& Zhen, S.-n. An exceptionally well-preserved theropod dinosaur from the Yixian Formation of China. Nature 391, 147-152 (1998).

37. Sato, T., Cheng, Y.-n., Wu, X.-c., Zelenitsky, D. K. \& Hsiao, Y.-f. A pair of shelled eggs inside a female dinosaur. Science 308, 375-375 (2005).

38. Hunt, G. L. \& Hunt, M. W. Clutch size, hatching success, and eggshellthinning in Western Gulls. Condor 75, 483-486 (1973).
39. Berg, C. et al. Embryonic exposure to oestrogen causes eggshell thinning and altered shell gland carbonic anhydrase expression in the domestic hen. Reproduction 128, 455-461 (2004)

40. Hirsch, K. F., Stadtman, K. L., Miller, W. E. \& Madsen, J. H. Upper Jurassic dinosaur egg from Utah. Science 243, 1711-1713 (1989).

41. Hirsch, K. F. Pathological amniote eggshell-fossil and modern. In (eds Darren, H. T. \& Kenneth C.). Mesozoic Vertebrate Life 378-392 (Indiana University Press, Bloomington, 2001).

42. Coles, B. H. \& Krautwald-Junghanns, M. Essentials of Avian Medicine and Surgery Vol. 12 (Wiley Online Library, 2007)

43. Erben, H., Hoefs, J. \& Wedepohl, K. Paleobiological and isotopic studies of eggshells from a declining dinosaur species. Paleobiology 5, 380-414 (1979).

44. Romanoff, A. L. \& Romanoff, A. J. The Avian Egg (John Wiley, New York, NY, 1949).

45. Rosen, L. B. Avian reproductive disorders. J. Exot. Pet. Med. 21, 124-131 (2012).

46. Bushnell, L. D. \& Maurer, O. Some Factors Influencing the Bacterial Content and Keeping Quality of Eggs Vol. 201 (Kansas State Agricultural College, Experiment Station, Topeka, Kansas, 1914).

47. Solomon, S. E. Egg \& Eggshell Quality (Iowa State University Press, Ames, IA, 1997).

48. Playle, M. A Point of Interest. Copeland Bird Obs. Rep., County Down, 50 (1975).

49. Wilson, P. W. et al. Understanding avian egg cuticle formation in the oviduct: a study of its origin and deposition. Biol. Reprod. 97, 39-49 (2017).

50. Harcourt-Brown, N. H. Torsion and displacement of the oviduct as a cause of egg-binding in four psittacine birds. J. Avian Med. Surg. 10, 262-267 (1996)

51. Kossack, C. W. An egg-bound mourning dove. Auk 73, 129-130 (1956)

52. Schweitzer, M. H. et al. Late Cretaceous avian eggs with embryos from Argentina. J. Vertebr. Paleontol. 22, 191-195 (2002).

53. Varricchio, D. J. \& Jackson, F. D. Reproduction in Mesozoic birds and evolution of the modern avian reproductive mode. Auk 133, 654-684 (2016)

54. Wiemann, J., Yang, T.-R. \& Norell, M. A. Dinosaur egg colour had a single evolutionary origin. Nature 563, 555-558 (2018).

55. Wiemann, J. et al. Dinosaur origin of egg color: oviraptors laid blue-green eggs. PeerJ 5, e3706 (2017).

56. Lee, A. H. \& Werning, S. Sexual maturity in growing dinosaurs does not fit reptilian growth models. Proc. Natl. Acad. Sci. USA 105, 582-587 (2008).

57. O'Connor, J. et al. Medullary bone in an Early Cretaceous enantiornithine (Aves) and discussion regarding its identification in fossils. Nat. Commun. 9 , 5169 (2018)

58. Chinsamy, A. \& Tumarkin-Deratzian, A. Pathologic bone tissues in a turkey vulture and a nonavian dinosaur: implications for interpreting endosteal bone and radial fibrolamellar bone in fossil dinosaurs. Anat. Rec.: Adv. Integr. Anat. Evolut. Biol. 292, 1478-1484 (2009).

59. Chinsamy, A., Chiappe, L. M., Marugán-Lobón, J., Chunling, G. \& Fengjiao, Z. Gender identification of the Mesozoic bird Confuciusornis sanctus. Nat. Commun. 4, 1381 (2013).

60. Prondvai, E. Medullary bone in fossils: function, evolution and significance in growth curve reconstructions of extinct vertebrates. J. Evol. Biol. 30, 440-460 (2016).

61. Canoville, A., Zanno, L. E., Zheng, W.-X. \& Schweitzer, M. H. New data on the skeletal distribution, microstructure, and chemistry of medullary bone in Neornithes - Paleobiological implications. In 5th International Paleontological Congress, Abstract Book, Vol. 912 (Paris, 2018)

62. O'Connor, J. K., Wang, M., Zheng, X.-T., Wang, X.-L. \& Zhou, Z.-H. The histology of two female Early Cretaceous birds. Vertebr. Palasiat. 52, 112-128 (2014).

63. Erickson, G. M. et al. Was dinosaurian physiology inherited by birds? Reconciling slow growth in Archaeopteryx. PLoS ONE 4, e7390 (2009)

64. O'Connor, J. K., Wang, M., Zhou, S. \& Zhou, Z. Osteohistology of the Lower Cretaceous Yixian Formation ornithuromorph (Aves) Iteravis huchzermeyeri. Palaeontol. . Electron. 18, 1-11 (2015).

65. Chiappe, L. M., Marugán-Lobón, J. \& Zhou, Z. Life history of a basal bird: morphometrics of the Early Cretaceous Confuciusornis. Biol. Lett. 4, 719-723 (2008).

66. Erickson, G. M., Rogers, K. C., Varricchio, D. J., Norell, M. A. \& Xu, X. Growth patterns in brooding dinosaurs reveals the timing of sexual maturity in non-avian dinosaurs and genesis of the avian condition. Biol. Lett. 3 , 558-561 (2007).

67. Wang, X. et al. Insights into the evolution of rachis dominated tail feathers from a new basal enantiornithine (Aves: Ornithothoraces). Biol. J. Linn. Soc 113, 805-819 (2014).

68. Mayr, G. Avian Evolution: The Fossil Record of Birds and Its Paleobiological Significance (John Wiley \& Sons, New York, 2016).

69. Zheng, X., Wang, X., O'connor, J. \& Zhou, Z. Insight into the early evolution of the avian sternum from juvenile enantiornithines. Nat. Commun. 3, 1116 (2012). 
70. O'Connor, J. K. \& Zhou, Z. A redescription of Chaoyangia beishanensis (Aves) and a comprehensive phylogeny of Mesozoic birds. J. Syst. Palaeontol. 11, 889-906 (2013).

71. Field, D. J. et al. Complete Ichthyornis skull illuminates mosaic assembly of the avian head. Nature 557, 96 (2018).

72. Harris, J. D., Lamanna, M. C., You, H.-1., Ji, S.-a. \& Ji, Q. A second enantiornithean (Aves: Ornithothoraces) wing from the Early Cretaceous Xiagou Formation near Changma, Gansu Province, People's Republic of China. Can. J. Earth Sci. 43, 547-554 (2006).

73. Goloboff, P. A., Farris, J. S. \& Nixon, K. C. TNT, a free program for phylogenetic analysis. Cladistics 24, 774-786 (2008).

74. Goloboff, P. A., Carpenter, J. M., Arias, J. S. \& Esquivel, D. R. M. Weighting against homoplasy improves phylogenetic analysis of morphological data sets. Cladistics 24, 758-773 (2008).

75. Horner, J. R. Paleontology: a cock's comb on a duck-billed dinosaur. Curr. Biol. 24, R85-R86 (2014).

\section{Acknowledgements}

We thank Hua Xiang for SEM and EDS spectra analyses, Wei Gao for photography, and Pengfei Yin for CT-scanning. We thank Tzuruei Yang for discussions about the cuticle chemistry, and Holly Woodward for discussions about the femoral histology. For funding, we thank the National Natural Science Foundation of China (Grant No. 41688103), the Chinese Academy of Sciences-President's International Fellowship Initiative (CAS-PIFI) program, and the Strategic Priority Research Program of Chinese Academy of Sciences (Grant Number: XDB26000000).

\section{Author contributions}

A.M.B. and J.O'C. designed the study. A.M.B., J.O'C., S.Z., Z.L., Q.W., X.Z. collected the data. A.M.B., J.O'C., S.Z., Z.L. performed the research. A.M.B., J.O'C., M.C.L. and Z.Z. wrote the paper.

\section{Additional information}

Supplementary Information accompanies this paper at https://doi.org/10.1038/s41467019-09259-x.

Competing interests: The authors declare no competing interests.

Reprints and permission information is available online at http://npg.nature.com/ reprintsandpermissions/

Journal peer review information: Nature Communications thanks the anonymous reviewers for their contribution to the peer review of this work.

Publisher's note: Springer Nature remains neutral with regard to jurisdictional claims in published maps and institutional affiliations.

\begin{abstract}
(c) (i) Open Access This article is licensed under a Creative Commons Attribution 4.0 International License, which permits use, sharing, adaptation, distribution and reproduction in any medium or format, as long as you give appropriate credit to the original author(s) and the source, provide a link to the Creative Commons license, and indicate if changes were made. The images or other third party material in this article are included in the article's Creative Commons license, unless indicated otherwise in a credit line to the material. If material is not included in the article's Creative Commons license and your intended use is not permitted by statutory regulation or exceeds the permitted use, you will need to obtain permission directly from the copyright holder. To view a copy of this license, visit http://creativecommons.org/ licenses/by/4.0/.
\end{abstract}

(C) The Author(s) 2019 